\title{
GEOLOGIA DA FOLHA DE AGUAÍ, SP
}

\author{
Anna Artemisia Barracco de AZEVEDO* \\ Marcos MASSOLI*
}

\begin{abstract}
RESUMO
A folha de Aguaí situa-se na borda oriental da bacia sediinentar do Paraná, incluindo-se parte do embasamento cristalino.

As rochas cristalinas estão representadas pelo Complexo Pinhal (pré-cambriano superior). Constituem-se de granitos e migmatitos de texturas e estruturas variadas.

A coluna sedimentar é composta pelo Subgrupo Itararé (Permo-Carbonifero), Formação Piraçununga (Terciário) e sedimentos aluvionares (Quaternário). O diabásio ocorre intrusivo no Subgrupo Itararé, notadamente na porção centro-norte da folha.

O Subgrupo Itararé constitui-se de siltitos, arenitos, diamictitos, ritmitos e argilitos que se distribuem em posições variadas na unidade.

O Cenozóico está representado pela Formação Piraçununga, composta por areias e cascalheiras basais, e por depósitos quaternários arenosos associados às planícies aluviais dos rios principais.
\end{abstract}

\begin{abstract}
The Aguaí area comprehends oriental Paraná Basin part and crystalline basement. The Pinhal Complex crystalline rocks (upper precambrian) are characterized by granites and migmatites presenting variated structures and textures.

The sedimentary rocks belongs to the Itararé Subgroup (Permian-Carboniferous), Piraçununga Formation (Tertiary) and to alluvial sediments (Quaternary). In the Itararé Subgroup occur diabase intrusions specially in the central north part of the area.

The Itararé Subgroup sediments, sandstones, siltstones, diamictites and shales are disposed deranged in the whale unit.

The Cenozóic comprehends Piraçununga Formation (sands and basal conglomerates) and quaternary (alluvial plains) along the main rivers.
\end{abstract}

\section{INTRODUÇÃO}

Este trabalho apresenta os resultados obtidos no mapeamento geológico da folha de Aguaí, onde ocorrem rochas précambrianas e rochas sedimentares da Bacia do Paraná. Foi executado na escala 1:50.000, sendo parte do Projeto Levantamento Geológico de Formações Superficiais em desenvolvimento pelo Instituto Geológico. Teve por finalidade obter informações que pudessem contribuir para maior conhecimento das unidades estratigráficas da área, para determinação de suas distribuições espaciais, relações de contato, seu comportamento estrutural e suas ocorrências minerais.

A área mapeada está compreendida pelos meridianos $46^{\circ} 45^{\prime}-47^{\circ} 00^{\prime} \mathrm{W}$ e $22^{\circ} 00^{\prime}-22^{\circ} 15^{\prime}$ S. Além da cidade de Aguaí, inclui parte da cidade de Espírito Santo do Pinhal. Dista cerca de $160 \mathrm{~km}$ de São Paulo, tendo como vias de acesso as rodovias Bandeirantes - Anhanguera (até Campinas) e a rodovia SP-340 (altura do $\mathrm{km} \mathrm{184).}$

\section{METODOLOGIA}

$\mathrm{O}$ método de trabalho consistiu na combinação de interpretação de fotos aéreas na escala 1:25.000, mapeamento de campo e elaboração do mapa geológico. Foram coletadas amostras de rochas sedimentares para execução de análises granulométricas, elaboradas através da combinação de processo de pipetagem e peneiramento (SUGUIO, 1973), que ti-

*Instituto Geológico - Caixa Postal 8772 - 01000 - São Paulo, SP, Brasil 
veram por finalidade mostrar a variação das propriedades dos sedimentos.

\section{TRABALHOS PRÉVIOS}

Dentre os trabalhos executados na região, referentes às rochas sedimentares, destacam-se: MEZZALIRA (1965), ANDRADE \& SOARES (1971), DAEE (1974), KAEFER et alii (1977), COTTAS et alii (1981).

Esses autores mostram a dificuldade em se estabelecer uma nomenclatura para os sedimentos paleozóicos da folha de Aguaí, tendo sido propostos para a mesma unidade estratigráfica os termos: Grupo Tubarão; Formação Aquidauana; Formação Aquidauana + Formação Itararé indiferenciadas; Grupo Itararé indiviso; Subgrupo Itararé e Formação Aquidauana.

COTTAS et alii (1981) reconheceram depósitos cenozóicos que se distribuem sobre os sedimentos paleozóicos, prolongando-se para as folhas de Rio Capetinga, a oeste, e São João da Boa Vista, a norte. Até então esses sedimentos inconsolidados modernos tinham sido mapeados pelos autores citados anteriormente como sendo solo de alteração de rochas do Grupo Tubarão.

As intrusivas básicas e as rochas do embasamento cristalino foram objeto de análise detalhada nos trabalhos de KAEFER et alii (1977) e WERNICK (1978).

\section{GEOMORFOLOGIA}

A área mapeada compreende duas províncias geomorfológicas: Planalto Atlântico (zona da Serrania de Lindóia) e Depressão Periférica (zona do Mogi Guàçu), conforme divisão proposta no Mapa Geomorfológico do Estado de São Paulo (IPT, 1981).

Desenvolvida em sedimentos do Subgrupo Itararé, a Depressão Periférica apresenta relevo uniforme de colinas onduladas, com altitude máxima em torno de $750 \mathrm{~m}$ no interflúvio do rio Itupeva e córrego das Matas, o que dá um desnível de aproximadamente $80 \mathrm{~m}$. A cota mínima dessa província geomorfológica é de $600 \mathrm{~m}$ nos extremos noroeste e sudoeste da folha, respectivamente nos vales do córrego de Amaro $^{\circ}$ Nunes e rio Oriçanga.

A uniformidade topográfica é interrompida a leste de Aguaí por um sill de diabásio, com cerca de 130 m de espessura, constituindo um relevo localmente escarpado, com altitude máxima de $910 \mathrm{~m}$, representando uma área, de aproximadamente $50 \mathrm{~km}^{2}$, sobrelevada em relação à Depressão Periférica e ao Planalto Atlântico, situada no limite dessas duas províncias geomorfológicas.

A drenagem na área sedimentar mostra padrão dendrítico, com os rios principais apresentando baixo gradiente, o que permite a formação de planícies aluviais em grande parte de seus cursos.

O Planalto Atlântico apresenta topografia mais acentuada principalmente junto à cabeceira do ribeirão dos Porcos, com altitudes de até $980 \mathrm{~m}$, que é o ponto mais alto da região. Entretanto, a delimitação das formas de relevo não corresponde exatamente ao limite entre a bacia sedimentar e o cristalino. Próximo a esse limite, o embasamento cristalino compõe uma topografia pouco acentuada, com altitudes de até $800 \mathrm{~m}$, para se tornar mais elevada em direção a lestesudeste da folha, formando morros de topos arredondados, com perfis retilínios a convexos.

A drenagem no Planalto Atlântico mostra padrão geral dendrítico, com trechos retilíneos condicionados por alinhamentos estruturais, com direção principal NE-SW, alta densidade e alto gradiente, razão pela qual as planícies aluviais são restritas. Porém, na parte nordeste da folha o rio Jaguari-Mirim e o ribeirão dos Porcos, em seus baixos cursos, constituem amplas planícies aluvionares, como a do ribeirão dos Porcos, com $15 \mathrm{~km}$ de extensão e largura, formando depósitos arenosos de importância econômica.

\section{ESTRATIGRAFIA}

A geologia da área está representada pelo Complexo Pinhal, do PréCambriano Superior (granitos e migmatitos); Subgrupo Itararé, de idade Permo-Carbonífera (siltitos, arenitos, diamictitos, ritmitos e argilitos); Formação Piraçununga, do Terciário (areias e cascalheiras); e sedimentos quaternários (areias e argilas). Ocorrem também rochas ígneas básicas (diabásios) intrusivas no Subgrupo Itararé (Fig. 1).

A parte sedimentar constitui uma faixa de afloramento com largura máxima 
de $18 \mathrm{~km}$ na porção norte da área, diminuindo para $10 \mathrm{~km}$ no extremo sul da folha.

\subsection{Pré-cambriano}

As rochas cristalinas ocorrem numa faixa de exposição com largura máxima atingindo $16 \mathrm{~km}$ no limite sul da folha.

Litologicamente constituem-se de rochas graníticas e migmatíticas de idade brasiliana, pertencentes ao Complexo Pinhal (WERNICK, 1978), resultantes da intrusão de massas graníticas em rochas do Grupo Amparo, do ciclo Transamazônico.

Os granitos apresentam texturas eqüigranulares (finas a grosseiras) e porfiróides, cores rosadas, esbranquiçadas e acinzentadas. Sua composição varia de granítica a quartzo-diorítica. Nos granitos porfiróides os fenocristais predominantes são de microclina, sendo que o oligoclásio ocorre em pequenas quantidades; a matriz apresenta textura eqüigranular média a grosseira, de composição quartzo-diorítica a granítica. Nesses corpos granitóides ocorrem diques e veios de quartzo e pegmatitos, encaixados em falhas e fraturas.

Os migmatitos constituem rochas híbridas, apresentando feições tanto magmáticas quanto metamórficas. A porção magmática, neossoma, apresenta cores claras, sendo constituída por quartzo e feldspato. A porção metamórfica, paleossoma, constitui-se por grande quantidade de minerais ferromagnesianos, tem cores escuras, podendo conservar a estrutura inicial após a transformação da rocha metamórfica por anatexia.

Quanto às relações entre o paleossoma e neossoma, os migmatitos apresentam mais comumente as estruturas dobrada, oftalmítica, schlieren, ptigmática e flebítica.

\subsection{Subgrupo Itararé}

$\mathrm{Na}$ região, esta unidade apresenta grande variação de fácies, nas quais não foi possível observar sua continuidade lateral e vertical. Como a subdivisão do Grupo Tubarão do ciclo glacial no Estado de São Paulo é um assunto bastante controvertido, adotou-se o termo "Itararé"' utilizado por FIGUEIREDO FILHO \& FRAKES (1968) na região de
Casa Branca-Mococa, situada a norte da área em estudo.

O Subgrupo Itararé é constituído por corpos interdigitados de siltitos, arenitos, ritmitos, diamictitos e argilitos, que aparecem em todos os níveis da unidade, com espessuras atingindo até algumas dezenas de metros, formas e dimensões variadas.

Os siltitos predominam no médio e alto vale do ribeirão do Oriçanga e são de cor marrom avermelhada, apresentando-se ora argilosos, ora arenosos, com acamamento plano-paralelo, às vezes exibindo microestratificação cruzada, partição conchoidal, podendo ser micáceos. Freqüentemente ocorrem intercalações de arenito fino de cor esbranquiçada, com espessuras de até $0,5 \mathrm{~m}$. Os melhores afloramentos dessa litologia podem ser vistos ao lado da capela de Santo Antonio; na Fazenda Quilombo e Fazenda Santa Rita das Posses. Neste local há diminuição gradual da granulometria dos sedimentos: na base do afloramento ocorre diamictito com matriz argilosa, passando para arenito fino sobreposto por siltito argiloso com intercalações de arenito.

Os arenitos apresentam coloração rósea, estrutura maciça ou plano-paralela, com grãos de quartzo arredondados a subarredondados. São friáveis devido à baixa percentagem de matriz argilosa (geralmente inferior a 10\%), mal selecionados, com distribuição granulométrica variando desde areia grossa até argila. Em média apresentam $75 \%$ de areia, onde predomina a fração areia fina. Ocorrem principalmente na parte sul da folha (próximo ao ribeirão Campo Redondo) e a sul da cidade de Aguaí (rodovia SP344 , junto ao rio Itupeva). Neste local aflora arenito de cor rosada, grosseiro a conglomerático, com seixos de quartzo e quartzito principalmente, com intercalações de arenito fino, exibindo localmente acamamento plano-paralelo. Estudo realizado por WU (1982) nesse afloramento indica tratar-se de arenito imaturo (subarcosiano), com predominância de zircão entre os minerais pesados não opacos $(7,2 \%)$ e magnetita e ilmenita entre os opacos $(70,2 \%)$. Esse sedimento teve por fonte rochas cristalinas intemperizadas como granitos, migmatitos e gnaisses, tendo posteriormente sofrido influência dos próprios sedimentos préexistentes. 
Ritmitos foram encontrados num único ponto, localizado no $\mathrm{km} 192$ da rodovia SP-340 (BJORNBERG et alii, 1966). Elaborou-se uma seção colunar desse afloramento (Fig. 2), a qual mostra a heterogeneidade litológica do Subgrupo Itararé: em $5 \mathrm{~m}$ de espessura ocorrem alternadamente arenitos, siltitos e ritmitos. Essa seqüência de camadas tem direção $\mathrm{N} 50^{\circ} \mathrm{W}$ e mergulho $8^{\circ} \mathrm{NE}$, estando localmente dobrada por intrusão de diabásio, sob a forma de dique, com $20 \mathrm{~m}$ de largura. A rocha básica, bastante altera$\mathrm{da}$, mostra estrutura orbicular, apresentando faixas concêntricas ora de minerais claros, ora de minerais escuros.

Os diamictitos têm cor marrom e ocorrem na porção centro-norte da área, próximo à confluência do rio Itupeva com o córrego da Cachoeira. Constituem depósitos clásticos mal selecionados, maciços, contendo seixos e blocos de diâmetros até decimétricos, compostos por quartzo e quartzito, com percentagem em torno de $10 \%$ da rocha, dispersos em matriz síltico-arenosa ou síltico-argilosa. A alta percentagem de finos em relação aos clásticos grosseiros sugere ambiente glacial na deposição desses sedimentos.

No extremo sul da folha, onde a altimetria atinge o ponto mais baixo $(600 \mathrm{~m})$, ocorrem argilitos marrons finamente laminados, intercalados em siltitos marrom claros, evidenciando sedimentação em ambiente lacustre. Esses sedimentos pelíticos, situados próximo ao distrito de Estiva (município de Mogi Guaçu), são explorados pelas indústrias cerâmicas como matéria prima na fabricação de telhas, ladrilhos, manilhas, etc, constituindo-se num dos principais recursos econômicos da região.

A variabilidade litológica do Subgrupo Itararé, tanto na vertical como na horizontal, mostra que a deposição dos sedimentos se deu em ambientes distintos. A ocorrência de fácies glaciais (diamictitos), lacustres (ritmitos) e flúvio-deltáica (arenitos e siltitos) em posições variáveis na coluna geológica da unidade evidenciam recorrências de subambientes.

O contato com o embasamento cristalino se faz através de discordância erosiva esculpida em rochas graníticomigmatíticas. As vezes ocorrem seixos e até matacões dentro dos sedimentos pouco acima do contato. Quando este se faz por falhamento, ocorre brecha composta por fragmentos de rochas ígneas e sedimentares.

Corpos isolados do Subgrupo Itararé ocorrem sobre o cristalino até pelo menos $12 \mathrm{~km}$ a leste do limite atual da bacia, indicando que a área da mesma era mais ampla, tendo sido reduzida por erosão. Constituem-se de siltitos arenosos ou arenitos finos de cores rosadas. Um desses corpos situa-se na altura do Km 206 da rodovia SP-346 (Pinhal São João da Boa Vista): compõem-se de siltito arenoso, ocupa altitude de até $940 \mathrm{~m}$, constituindo-se numa das ocorrências de maior altimetria do Itararé no Estado de São Paulo (a outra é a de Águas da Prata).

A espessura máxima aflorante do Subgrupo Itararé é superior a $100 \mathrm{~m}$ na cabeceira do rio da Itupeva, onde o topo dos sedimentos atinge a cota de $800 \mathrm{~m}$ e a base da escarpa por eles constituída está a cerca de $700 \mathrm{~m}$.

\subsection{Intrusivas Básicas}

Ocorrem na parte nor te da área, sendo caracterizadas pela presença de "terra roxa', cujas características são bastante similares"aos solos de alteração de rochas do Subgrupo Itararé, diferenciando-se, porém, destes últimos pela presença de magnetita em abundância.

A maior das intrusões localiza-se junto ao contato da bacia com o cristalino. É representada por um corpo alongado, constituindo sill que tem continuação para norte, adentrando-se na folha de São João da Boa Vista. Na área em estudo, possui direção NW, com cerca de $15 \mathrm{~km}$ de comprimento e $6,5 \mathrm{~km}$ de largura. Parte de seu contato oeste, com os sedimentos paleozóicos, se dá através de falha com direção NW, bloco levantado para SW, na qual encaixou-se o córrego da Laje. Medidas de diaclasamento realizadas numa pedreira de diabásio situada próximo ao referido córrego revelaram uma direção preferencial $\mathrm{N} 75^{\circ} \mathrm{W}$, coincidindo, portanto, com a direção do falhamento.

$\mathrm{Na}$ extremidade sul do corpo básico, uma falha de direção NE, evidenciada pela presença de escarpa, coloca o diabásio e os se dimentos em contato com o cristalino. Nesse caso, houve elevação do bloco SE. 
Outras intrusões básicas, porém de menor grandeza, ocorrem nos arredores de Aguaí. Pela forma como ocorrem em superfície aparentam ser lacólitos. Em subsuperfície, nesta cidade, há um sill de diabásio a $60 \mathrm{~m}$ de profundidade, conforme dados de sondagem realizada, próximo à estação ferroviária, para captação de água subterrânea.

\subsection{Cenozóico}

Os depósitos cenozóicos podem ser divididos em dois ciclos: o mais antigo, de idade provavelmente terciária (Formação Piraçununga) e o mais recente, relacionado às planícies de inundação atuais.

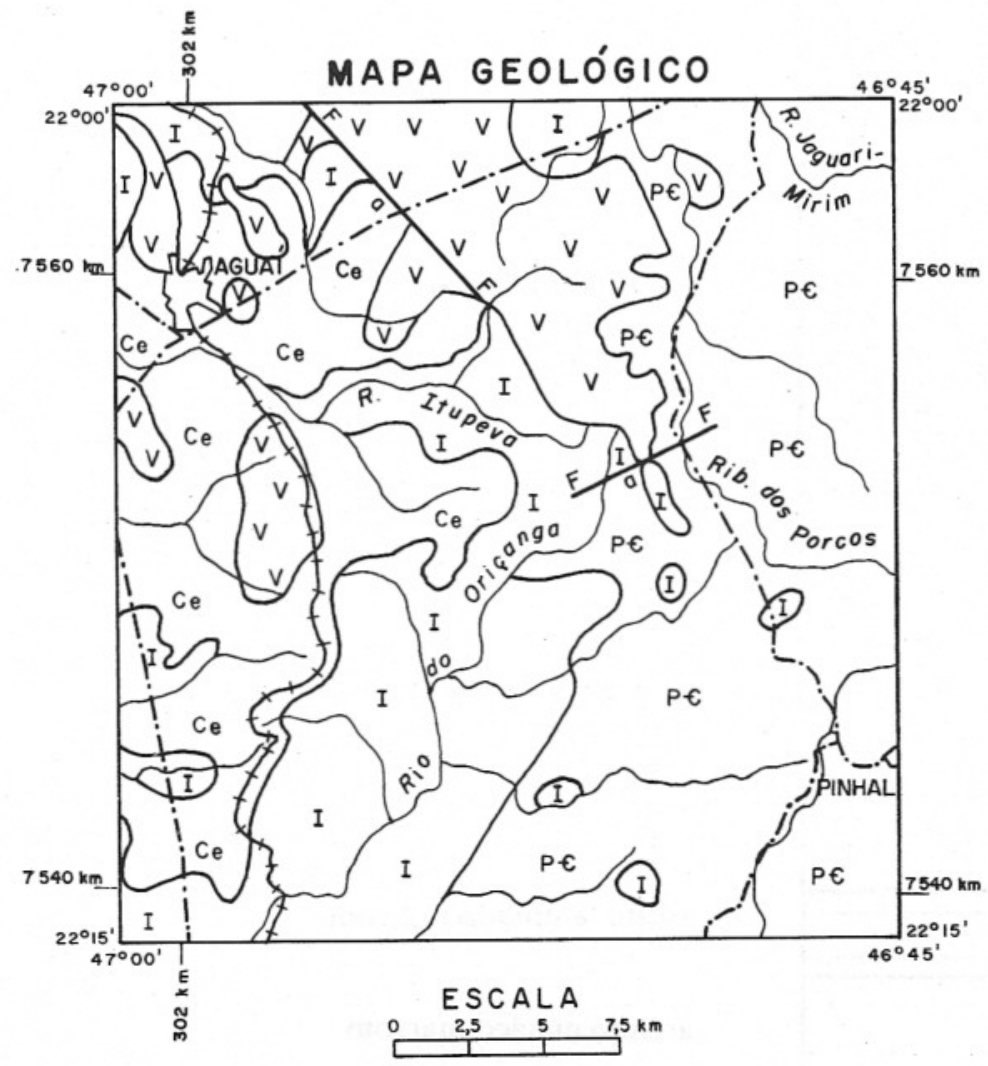

LOCALIZACÃO DA FOLHA NO ESTADO
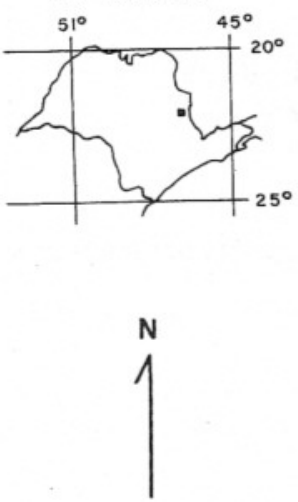

CONVENÇÕES

\section{GEOLÓGICAS GEOGRÁFICAS}

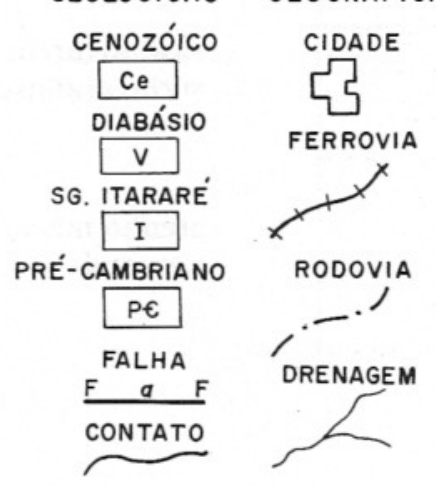

FIG. 1 


\section{SEÇÃO COLUNAR DO SG. ITARARÉ LOCAL: KM. 192 DA RODOVIA MOJI-GUAÇU-AGUAI}

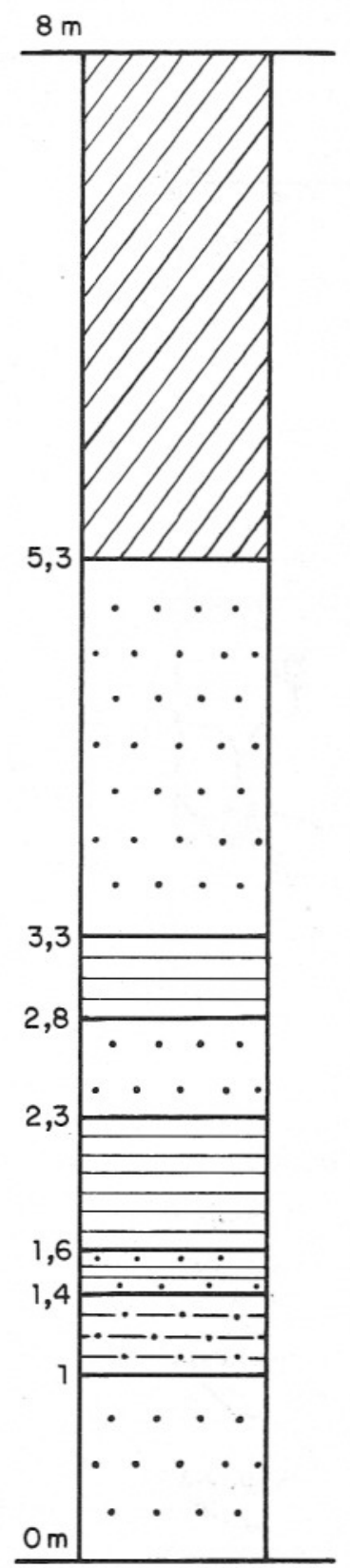

solo avermelhado

arenito maciço esbranquiçado

siltito laminado marrom

arenito maciço marrom

siltito laminado marrom

ritmito (arenito/argilito)

siltito argiloso marrom

arenito maciço de cores acinzentada, avermelhada e amarelada

FIG.2 
A Formação Piraçununga ocorre capeando superfícies erosivas esculpidas nas rochas do Subgrupo Itararé Constitui depósitos de espigão que se distribuem principalmente a oeste-sudoeste da folha, de relevo suave a levemente ondulado, ocupando altitudes que variam de 640 a 740m. Compõe-se de areias inconsolidadas, cuja distribuição granulométrica apresenta, em média, $68 \%$ de areia, $9 \%$ de silte e $23 \%$ de argila, pobremente selecionadas, tendo diâmetro médio equivalente às frações silte grosso e areia muito fina. Não apresentam qualquer tipo de estrutura sedimentar, devendo tratar-se de sedimentação efetuada graças a processo de coluviação. Na base da Formação Piraçununga, que raramente ultrapassa $10 \mathrm{~m}$ de espessura, ocorre freqüentemente uma linha de seixos constituída por seixos de quartzo e quartzito e fragmentos de limonita, disposta de forma discordante sobre as rochas do Subgrupo Itararé.

Cerca de $3 \mathrm{~km}$ a sul da estação ferroviária de Mato Seco há uma boçoroca com $100 \mathrm{~m}$ de comprimento e $10 \mathrm{~m}$ de profundidade, onde se observam sedimentos cenozóicos sobrejacentes às rochas do Subgrupo Itararé. No fundo da boçoroca ocorre siltito marrom, maciço ou com acamamento, sobreposto por uma camada de argila cor marrom chocolate, com cerca de $0,5 \mathrm{~m}$ de espessura, acima da qual aparece arenito friável, de cor amarelada, granulação fina a média, passando a grosseira em direção ao topo. Essa seqüência de rochas do Subgrupo Itararé está recoberta por sedimentos areno-argilosos, mal selecionados, sem estrutura sedimentar, espessura de $5 \mathrm{~m}$, de idade cenozóica.
Os depósitos recentes ocorrem como planícies aluvionares nos vales dos rios Jaguari-Mirim, Itupeva, Oriçanga e ribeirão dos Porcos, entre outros. São constituídos por areias de granulometrias variadas, com percentagens menores de silte e argila.

\section{CONCLUSÕES}

1 - O embasamento cristalino, pertencente ao Complexo Pinhal, é constituído por rochas graníticas e migmatíticas de texturas, estruturas e composições mineralógicas variadas.

2 - Devido à grande variabilidade litológica dos sedimentos paleozóicos, com mudanças tanto na vertical como na lateral, não foi possível a sua subdivisão estratigráfica em formações distintas.

3 - A complexidade litológica do Subgrupo Itararé se deve à interação de vários ambientes na deposição dos sedimentos, dentre os quais destacam-se o flúvio-deltáico (arenitos, siltitos e argilitos), glacial (diamictitos) e glácio - lacustre (ritmitos).

4 - A presença de sedimentos paleozóicos afastados do limite atual da bacia do Paraná evidencia que a mesma abrangia superfície bem maior que a atual.

5 - Os sedimentos cenozóicos, denominados Formação Piraçununga, são constituídos por areias argilosas inconsolidadas, muito pobremente selecionadas, cuja distribuição granulométrica apresenta, em média, $68 \%$ de areia, $9 \%$ de silte e $23 \%$ de argila. Não apresentam estrutura sedimentar e ocorrem nos espigões, ocupando altitudes que variam de 640 a $720 \mathrm{~m}$. São interpretados como sendo de origem coluvial.

\section{REFERÊNCIAS BIBLIOGRÁFICAS}

ANDRADE, S.M. de \& SOARES, P.C. 1971 Mapa geológico semidetalhado do centro leste de São Paulo; bacia do Paraná /Rio de Janeiro/ PETROBRÁS DESUL. Escala 1:100.000. (Relatório, 407 Anexo 26)

BJORNBERG, A.J.S. et alii 1966 Varvitos na bacia do rio Mogi Guaçu, SP. Ciência e Cultura, São Paulo, 18(3):313-319.

CO? TAS, L.R. et alii 1981 Divisão faciológica do bgrupo Itararé e da Formação Aquidauano nordeste do Estado de São Paulo. In:
SIMPÓSIO REGIONAL DE GEOLOGIA, 3. ${ }^{\circ}$, Curitiba. Atas. Curitiba, Sociedade Brasileira de Geologia. v.2 p.103-115.

FIGUEIREDO FILHO, M.P. \& FRAKES, L.A. 1968 Itararé Sub-group, Tubarão Group in the Mococa - Casa Branca region - São Paulo State. Boletim da Sociedade Brasileira de Geologia, São Paulo, 17(1):59-63.

KAEFER, L.Q. et alii 1977 Projeto Sapucai: relatório final geologia. São Paulo, CPRM/DNPM. v.1615p. 
Rev. IG, São Paulo, 5(1/2):39-46, jan./dez. 1984

MEZZALIRA, S. 1965 Folha geológica provisória de Mogi Mirim. São Paulo, Instituto Geográfico e Geológico.

SÃO PAULO. DEPARTAMENTO DE ÁGUAS E ENERGIA ELÉTRICA 1974 Estudo de águas subterrâneas, região administrativa 6 , resumo. São Paulo. v.l 75p.

SÃO PAULO. INSTITUTO DE PESQUISAS TECNOLÓGICAS 1981 Mapa geomorfológico do Estado de São Paulo. São Paulo. v.1 $94 p$.
SUGUIO, K. 1973 Introdução à sedimentologia. São Paulo, Edgard Blucher, EDUSP. 317p:

WERNICK, E. 1978 Contribuição à estratigrafia do Pré-cambriano do leste do Estado de Sâo Paulo e áreas vizinhas. Revista Brasileira de Geociências, São Paulo, 8(3):206-216.

WU, F.T. 1982 Minerais nas rochas arenosas do Subgrupo Itararé e Formação Aquidauana no centro leste do Estado de São Paulo. Geociências, Rin Claro, 1:7-27. 